\title{
RECOVERY OF NORMAL WEIGHT IN THE VARIOUS ORGANS OF ALBINO RATS ON REFEEDING \\ AFTER UNDERFEEDING FROM BIRTH FOR VARIOUS PERIODS*
}

\author{
C. M. JACKSON, M.S., M.D., ANd C. A. STEWART, Ph.D. \\ MINNEAPOLIS
}

Previous research by ourselves and others (summarized by Jackson and Stewart, ${ }^{1}$ 1918) has shown that in young animals underfed for various periods remarkable changes occur in the weights of the various organs and parts of the body. There is also evidence indicating that similar changes occur in malnourished human infants. While some organs during inanition tend to maintain approximately their normal relative weight, and others continue to grow, still others undergo losses. The organs affected and the extent of the changes involved vary according to the age of the individual and the length and character of the inanition.

The question naturally follows as to the process of recovery on abundant refeeding after various periods of inanition. Stewart ${ }^{2}$ has already shown that rapid recuperation occurs in rats refed after being held at maintenance (constant body weight) from the age of weaning ( 3 weeks) to about the age of puberty (10 or 12 weeks). The various organs and parts usually recover their normal relative weights within four weeks of refeeding. The object of the present investigation is to determine the extent of recovery on similar refeeding of rats which have been underfed from birth, during a period in which the changes due to underfeeding are much greater than at later periods (Stewart, ${ }^{3}$ 1918, 1919). The results may perhaps indicate the probability of recovery in the various organs of infants after periods of inanition, a clinical problem of obvious importance.

* From the Institute of Anatomy, University of Minnesota.

1. Jackson, C. M., and Stewart, C. A.: The Effects of Underfeeding and Refeeding on the Growth of the Various Systems and Organs of the Body, Minnesota Med. 1:403, 1918.

2. Stewart, Chester A.: Growth of the Body and of the Various Organs of Young Albino Rats after Inanition for Various Periods, Biol. Bull. 31:16, 1916.

3. Stewart, Chester A.: Changes in the Relative Weights of the Various Parts, Systems and Organs of Young Albino Rats Underfed for Various Periods, J. Exper. Zool. 25:301, 1918. Ibid. Changes in the Weights of the Various Parts, Systems and Organs in Albino Rats Kept at Birthweight for Various Periods, Am. J. Physiol. 48:67, 1919. 


\section{MATERIAL AND METHODS}

The albino rat (Mus norvegicus albinus) was used as heretofore, including complete data for 31 test rats ( 15 males, 16 females) and 22 controls (9 males, 13 females), the individuals being listed in Table 1. For intestinal lengths, 45 additional test rats (26 males, 19 females) and 24 controls (12 males, 12 females) were used, corresponding chiefly to the same individuals used in previous papers by Stewart ${ }^{3}$ (1918 and 1919). The letters "St" (Stewart) refer to the series, the number preceding the decimal point refers to the litter and the number following designates the individual rat. Thus, it is apparent that, for the most part, the test rats and controls were from the same litters. This is a matter of importance, especially in view of the comparatively small number of animals used, since it has been shown by Jackson ${ }^{4}$ and King ${ }^{5}$ that variability in weight within the litter is very much less than that of the rat population in general.

The rats were well cared for in the animal rooms of the Institute of Anatomy, and were kept as nearly as possible under uniform environment. varying only the nutritive conditions as desired. The necropsies were performed and the data carefully recorded by Stewart, the technic being the same as that described in our previous articles.

The test rats were all underfed by removal from the mother for various successive periods from birth up to the period of weaning (about three weeks), and later by feeding restricted amounts of whole wheat (Graham) bread, soaked in whole milk. Water (city supply, from Mississippi river) was also furnished. Some of the rats were underfed from birth to 3 weeks of age. The gross body weight during this time increased from about $5 \mathrm{gm}$. to only about $10 \mathrm{gm}$., whereas normally it would have increased to 20 or $25 \mathrm{gm}$. Some were similarly underfed from birth to 6 weeks (exact average being 45 days), reaching an average weight of 13 to $14 \mathrm{gm}$. (normal at this time being about $50 \mathrm{gm})$. In some, the underfeeding was prolonged from birth to the age of 10 weeks ( 66 days in group E, 67 days in group F) the body weight reaching about $16 \mathrm{gm}$. (normal about 100 to $120 \mathrm{gm}$.). These three groups were therefore in the same condition as those in which Stewart ${ }^{3}$ (1918) has determined the changes in the weights of the organs and parts at the end of the underfeeding period.

The first group (underfed from birth to 3 weeks), shown in Tables 1 and 2, were then placed on a full diet of bread and milk, and refed until they had reached body weights of approximately $25 \mathrm{gm}$., $50 \mathrm{gm}$. or $75 \mathrm{gm}$.. respectively. The second group (underfed to 6 weeks) were similarly refed until they had reached a body weight of about $75 \mathrm{gm}$. The third group (underfed to 10 weeks) were similarly refed, some to about $50 \mathrm{gm}$. and the others to about $75 \mathrm{gm}$., as shown in Tables 1 and 2 .

The normal controls were likewise killed in three groups, with approximate gross body weights of 25,50 and $75 \mathrm{gm}$., respectively, corresponding to the final body weights of the various test groups.

It is thus possible to compare directly the weights of organs in the controls and in the test groups, and to ascertain in each case to what extent they approach the normal for corresponding body weight. The difference is expressed in Table 2 as a percentage (plus or minus) in each case. The correction for differences in body weight between control and test groups is so slight that it was ignored. There is also

4. Jackson, C. M.: Postnatal Growth and Variability of the Body and of the Various Organs in the Albino Rat, Am. J. Anat. 15:1, 1913.

5. King, Helen D.: The Growth and Variability in Body Weight of the Albino Rat, Anat. Rec. 9:751, 1915. 
TABle 1.-Albino Rats Used. Individual Data for Sex, Age, Gross Body Weight and Body Length

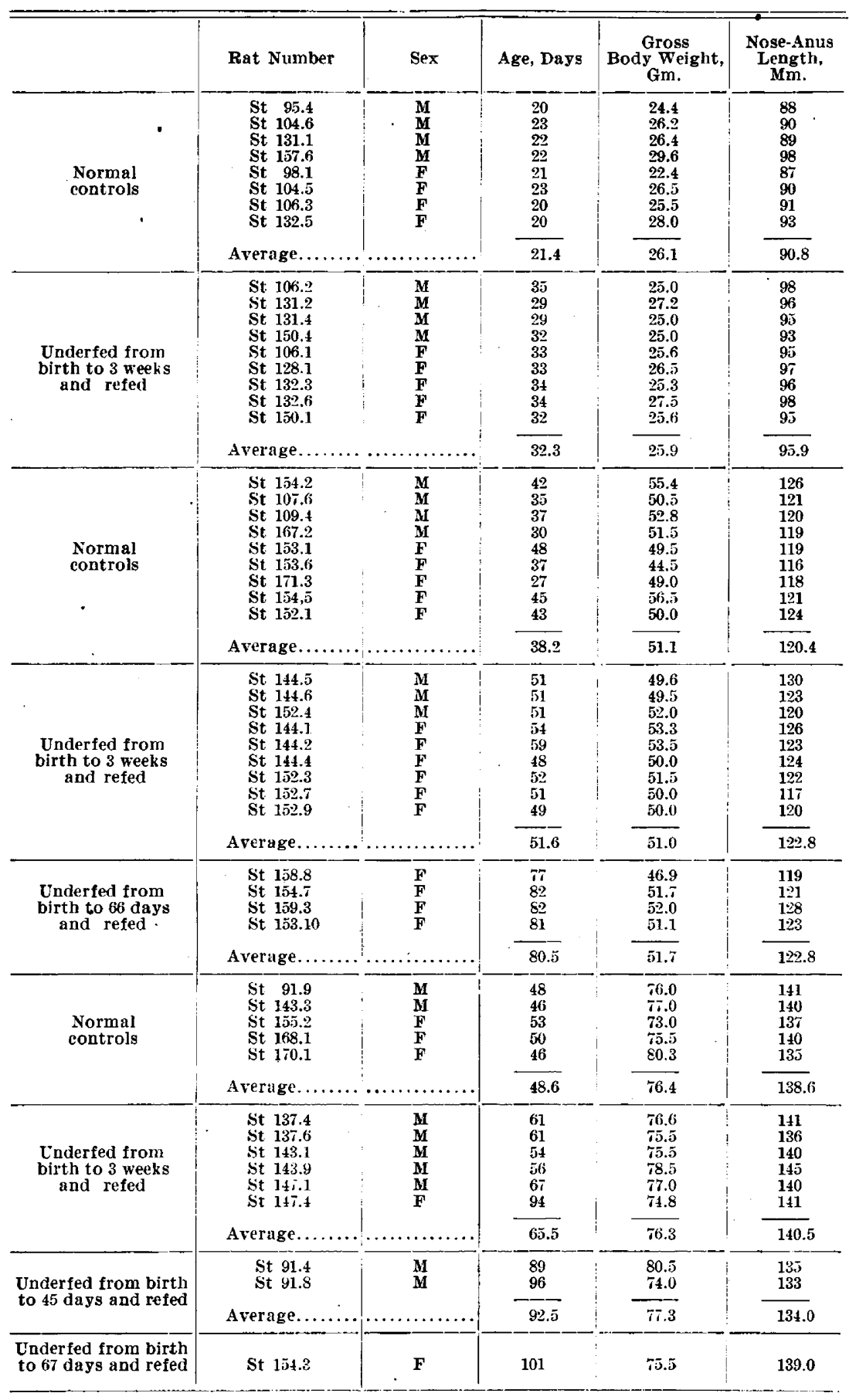




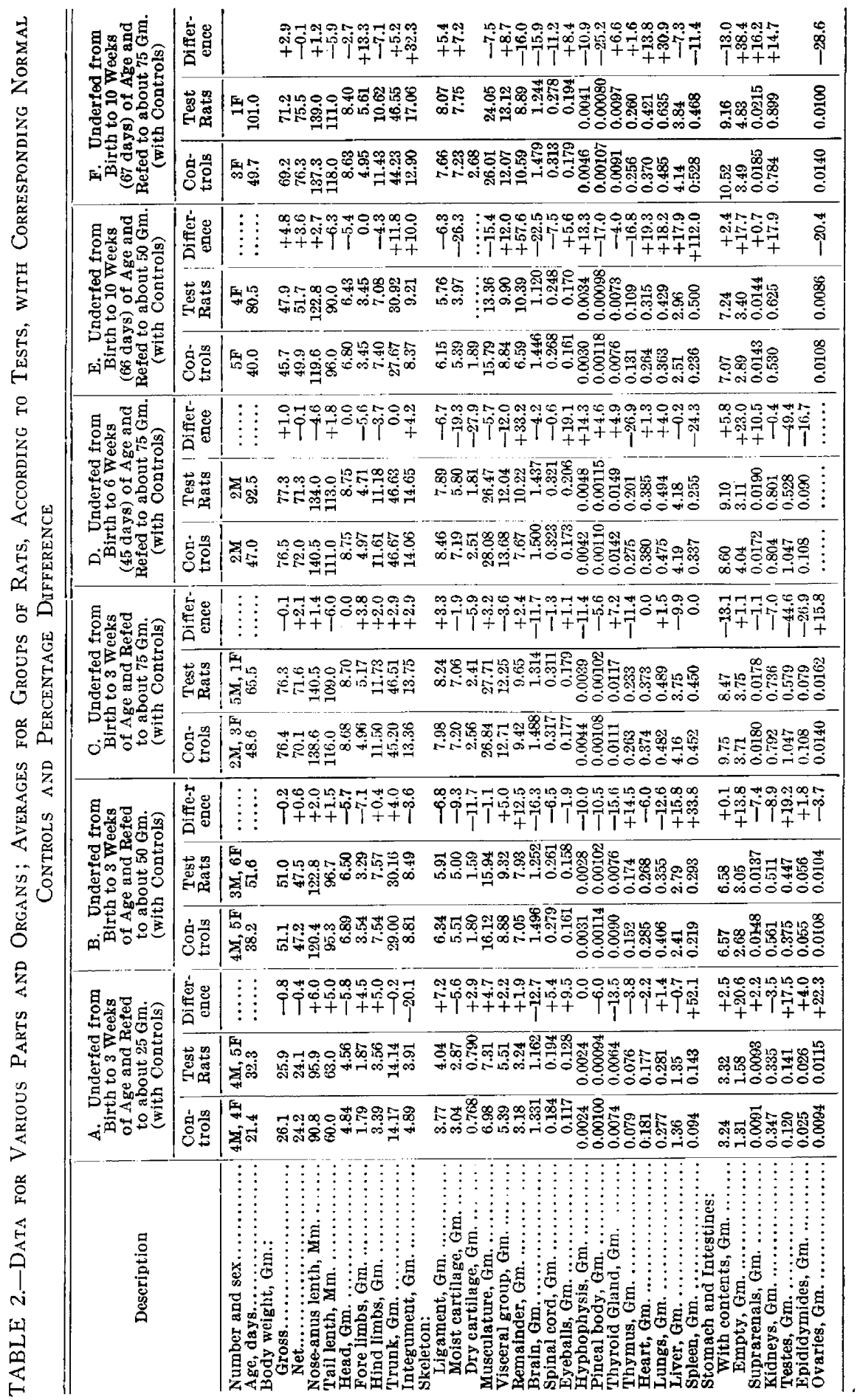


a slight error involved in computing the percentages from the average for the group, rather than for each individual separately. Finally, of course, due allowance must be made for experimental error and normal variability, in view of the comparatively small number of observations in each group. These considerations make it necessary to be cautious in drawing final conclusions, although the results in general seem to justify some provisional conclusions, as will appear later.

If the data for the normal control rats in the present series are compared with the normal tables of Donaldson, ${ }^{6}$ derived from the formulas of Hatai, ${ }^{7}$ a general agreement is found, although certain differences appear. As we have repeatedly noted, in the normal rats from the Minnesota and Missouri colonies, the weight of the liver is constantly lower, and that of the spleen higher, than the Wistar norm for rats of the same body length or weight (Jackson, ${ }^{4}$ Stewart, ${ }^{2,3}$ 1916 and 1918). In the present series, the body length in the normal rats averages slightly below the Wistar norm for animals of the same body weight, that is, our animals are relatively a little heavier for the same body length. The tails are likewise somewhat shorter in our series. The thymus is heavier than the Wistar norm for the corresponding age, usually also for the corresponding body weight. The empty stomach and intestines are lighter, and the ovaries somewhat heavier, than the Wistar norm. In the other organs, there is but slight or inconstant difference. It is uncertain whether the above differences mentioned are accidental (due to chance variation in the small series), environmental (due to differences in diet, temperature, etc.), or germinal (due to different varieties or strains of albino rats). At any rate, they emphasize the necessity of having direct controls in experimental work of this kind. The Wistar norm is, of course, also exceedingly valuable as a common standard, whereby variations in local strains may be recognized and compared.

In Table 1, the individual (gross) body weights and body lengths are given, which will show the variations within each group. For economy of space, only the averages are given in each group for the other data (Tables 2 and 3 ). The normal variability and correlation in the weight of the various organs has been studied by Jackson. ${ }^{4}$ The individual data in the present series, as heretofore, will be deposited in the Wistar Institute of Anatomy, Philadelphia, where they will be available to those interested.

6. Donaldson, H. H.: The Rat. Reference Tables and Data for the Albino Rat and the Norway Rat, Memoirs Wistar Inst. Anat. and Biol. 1915, No. 6.

7. Hatai, S.: On the Weights of the Abdominal and Thoracic Viscera, the Sex Glands, Ductless Glands and the Eyeballs of the Albino Rat (Mus norvegicus albinus) According to body weight, Am. J. Anat. 15:87, 1913. 
TABLE 3.-Average Length of Large and Small Intestines in the Various Groups of Albino Rats*

\begin{tabular}{|c|c|c|c|c|c|c|c|c|}
\hline & \multirow{2}{*}{$\begin{array}{l}\text { Age, } \\
\text { Days }\end{array}$} & \multirow{2}{*}{$\begin{array}{l}\text { Number } \\
\text { and } \\
\text { Sex }\end{array}$} & \multirow{2}{*}{$\begin{array}{l}\text { Gross } \\
\text { Body, } \\
\text { Weight, } \\
\text { Gm. }\end{array}$} & \multirow{2}{*}{$\begin{array}{l}\text { Body } \\
\text { Length, } \\
\text { Mm. }\end{array}$} & \multicolumn{2}{|c|}{$\begin{array}{l}\text { Length of } \\
\text { Intestine }\end{array}$} & \multirow{2}{*}{$\begin{array}{l}\text { Ratio } \\
\text { of } \\
\text { Intes- } \\
\text { tine to } \\
\text { Body } \\
\text { Length }\end{array}$} & \multirow{2}{*}{$\begin{array}{c}\text { Ratio } \\
\text { of } \\
\text { Small to } \\
\text { Iarge } \\
\begin{array}{c}\text { Intes- } \\
\text { tine }\end{array}\end{array}$} \\
\hline & & & & & $\begin{array}{l}\text { Large, } \\
\text { Im. }\end{array}$ & $\begin{array}{l}\text { Small, } \\
\text { Mm. }\end{array}$ & & \\
\hline $\begin{array}{l}\text { A. Normal } \\
\text { controls }\end{array}$ & $\begin{array}{r}1 \\
9 \\
13 \\
21 \\
39 \\
49\end{array}$ & $\begin{array}{l}1 \mathrm{M}, \mathrm{I} \\
6 \mathrm{~F} \\
3 \mathrm{M}, \mathrm{F} \\
3 \mathrm{M}, 3 \mathrm{~F} \\
3 \mathrm{M}, 4 \mathrm{~F} \\
2 \mathrm{M}, 3 \mathrm{~F}\end{array}$ & $\begin{array}{r}4.3 \\
10.0 \\
15.5 \\
25.8 \\
50.9 \\
76.4\end{array}$ & $\begin{array}{l}46 \text { (est.) } \\
63 \\
74 \\
90 \\
121 \\
139\end{array}$ & $\begin{array}{r}20.0 \\
41.8 \\
45.7 \\
66.3 \\
99.9 \\
117.0\end{array}$ & $\begin{array}{l}179 \\
307 \\
355 \\
501 \\
682 \\
892\end{array}$ & $\begin{array}{l}4.3 \\
5.5 \\
5.4 \\
6.3 \\
6.5 \\
7.3\end{array}$ & $\begin{array}{l}9.0 \\
7.4 \\
7.8 \\
7.6 \\
7.8 \\
7.6\end{array}$ \\
\hline $\begin{array}{l}\text { 13. Underfed } \\
\text { from birth } \\
\text { to age } \\
\text { indicated }\end{array}$ & $\begin{array}{l}19 \\
22 \\
42 \\
67\end{array}$ & $\begin{array}{rl}2 \mathrm{M}, 2 & \mathrm{~F} \\
15 \mathrm{M}, 9 \mathrm{~F} \\
4 \mathrm{M}, 3 \mathrm{~F} \\
7 \mathrm{M}, 4 \mathrm{~F}\end{array}$ & $\begin{array}{r}5.0 \\
10.1 \\
13.7 \\
15.3\end{array}$ & $\begin{array}{l}56.0(+22) \\
68.0(+8) \\
79.3( \\
85.3(+15)\end{array}$ & $\begin{array}{l}36.2(+81) \\
48.3(+15) \\
64.3 \\
67.3(+47)\end{array}$ & $\begin{array}{l}239(+25) \\
349(+14) \\
506 \\
553(+56)\end{array}$ & $\begin{array}{l}4.9 \\
5.8 \\
7.2 \\
7.3\end{array}$ & $\begin{array}{l}6.6 \\
7.2 \\
7.9 \\
8.2\end{array}$ \\
\hline $\begin{array}{l}\text { C. Refed after } \\
\text { underfeeding } \\
\text { from birth to } \\
3 \text { weeks of age }\end{array}$ & $\begin{array}{r}33 \\
.52 \\
66\end{array}$ & $\begin{array}{l}4 \mathbf{M}, 5 \mathrm{~F} \\
3 \mathrm{M}, 5 \mathrm{~F} \\
5 \mathrm{M}, 1 \mathrm{~F}\end{array}$ & $\begin{array}{l}25.9 \\
50.8 \\
76.3\end{array}$ & $\begin{array}{r}96.0(+6) \\
122.4(+1) \\
140.5(+1)\end{array}$ & $\begin{array}{r}76.4(+15) \\
97.0(-3) \\
105.3(-10)\end{array}$ & $\begin{array}{l}560(+12) \\
745(+9) \\
832(-7)\end{array}$ & $\begin{array}{l}6.6 \\
6.9 \\
6.7\end{array}$ & $\begin{array}{l}7.3 \\
7.7 \\
7.9\end{array}$ \\
\hline $\begin{array}{l}\text { D. Refed after } \\
\text { underfeeding } \\
\text { from birth to } \\
6 \text { weeks of age }\end{array}$ & 93 & $2 \mathrm{M}$ & i九.3 & $134(-4)$ & $122.5(+5)$ & $877(-2)$ & 7.5 & 7.2 \\
\hline $\begin{array}{l}\text { F. Refed after } \\
\text { underfeeding } \\
\text { from birth to } \\
10 \text { weeks of age }\end{array}$ & $\begin{array}{r}81 \\
101\end{array}$ & $\begin{array}{ll}4 & \mathrm{~F} \\
1 & \mathrm{~F}\end{array}$ & $\begin{array}{l}51.9 \\
75.5\end{array}$ & $\begin{array}{l}123(+2) \\
139(+0)\end{array}$ & $\begin{array}{l}107.3(+7) \\
114.0(-3)\end{array}$ & $\begin{array}{l}802(+18) \\
798(-10)\end{array}$ & $\begin{array}{l}7.4 \\
6.6\end{array}$ & $\begin{array}{l}7.5 \\
7.0\end{array}$ \\
\hline
\end{tabular}

* Figures in parenthesis indicate percentage changes of corresponding part, in comparison with normal controis of nearly the same body weight.

Body Weight. - The average time required to reach the body weights of 25,50 and $75 \mathrm{gm}$. on refeeding in the various groups may be learned from the data in Table 2 . Thus, Group A, underfed from birth to three weeks, required an average of 11.3 days (final age 32.3 days) of ample refeeding to reach a body weight of about $25 \mathrm{gm}$. Similarly to reach about 50 (51) gm. (Group B) required 30.6 days, and to reach 75 (76.3) gm. (Group $C$ ) required 44.5 days of refeeding.

In Group D, underfed from birth to about 6 weeks ( 45 days), 47.5 days of ample refeeding were required to reach a final body weight of about 75 (77.3) gm.

In Group E, underfed from birth to about 10 weeks (66 days), only 14.5 days of ample refeeding were required to reach a body weight of $50 \mathrm{gm}$. This is astonishingly rapid growth, in comparison with the time required for Group $B$ to reach the same body weight. In Group F, similarly underfed to ten weeks (67 days), only 34 days of refeeding were required to reach a body weight of $75 \mathrm{gm}$. This is likewise a shorter time than that required to reach the same body weight by Groups $C$ and $D$, which had been underfed for shorter periods.

This more rapid recovery of body weight in the groups underfed to ten weeks of age is in part explained by the fact that they had reached a somewhat higher body weight at the end of the underfeeding period. Some time would naturally be required on refeeding 
to enable the rats at 10 or $13 \mathrm{gm}$. body weight to reach the initial weight of about $16 \mathrm{gm}$. which had been attained by Groups $\mathrm{E}$ and $\mathrm{F}$ at the end of the underfeeding period.

But this difference in initial body weight is insufficient to explain the shorter time of refeeding required for Groups $E$ and F. Even when all due allowance is made, the surprising fact remains that the recovery in body weight after the longer underfeeding period is more rapid than after the shorter underfeeding periods. This, of course, might be due to an accidental variation, as individuals differ considerably in their resistance to inanition and in power of recuperation. That it is not merely an accidental variation, however, is indicated by the somewhat similar results of Stewart, ${ }^{2}$ who found that rats amply refed after maintenance by underfeeding from 3 to 6,8 or 10 weeks of age actually grow more rapidly than normally, so as to overtake later the normal controls of the same age. In Stewart's series it also appears that for a time the growth on refeeding was slightly more rapid in the groups (especially the females) underfed to 10 weeks (compare his Charts A and B). This surprising phenomenon of more rapid growth on refeeding does not necessarily mean that those underfed for the longer periods will ultimately reach full normal body weight, although this apparently happened in most of Stewart's earlier series (Jackson and Stewart ${ }^{1}$ ). It furthermore does not necessarily mean that the various organs and parts of the body have more quickly regained their normal proportions in the groups refed after the longer underfeeding periods. As will be shown later, this is frequently not the case.

The phenomenon of unusually rapid growth following periods of growth suppression has previously been noted by Hatai, ${ }^{8}$ Ferry, ${ }^{9}$ and Osborne and $\mathrm{Mendel}^{10}$ in the rat, as well as in other animals (see citations by Stewart ${ }^{2}$ ). A similar phenomenon has likewise been noted in children by Coudereau, ${ }^{11}$ Pagliani, ${ }^{12}$ Schloss, ${ }^{13}$ Boas $^{14}$ and others.

8. Hatai, S.: Effect of Partial Starvation, Followed by a Return to Normal Diet, on the Growth of the Body and Central Nervous System of Albino Rats, Am. J. Physiol. 18:309, 1907.

9. Ferry, Edna L.: The Rate of Growth of the Albino Rat, Anat. Rec. 7: 1913, No. 12 .

10. Osborne, T. B., and Mendel, L. B.: The Resumption of Growth after Long-Continued Failure to Grow, J. Biol. Chem. 23: 1915. Ibid. Acceleration of Growth after Retardation, Am. J. Physiol. 40: No. 1, 1916.

11. Coudereau: Récherches chimiques et physiologiques sur l'alimentation des enfants, Paris, 1869. (Cited by Hatai, Footnote 8.)

12. Pagliani: Giornale della reale Società italiana d'igiene, Milano 1: 1879. (Cited by Hatai, Footnote 8 .) 1911.

13. Schloss, E.: Die Pathologie des Wachstums im Säuglingsalter, Berlin,

14. Boas, F.: The Growth of Children, Science, New Series 36:815, 1912. 
Body Length and Tail Length.- The body length is measured from the tip of the nose to the anus, the trunk being slightly extended. Stewart $^{3}$ (1918) found that in rats underfed from birth (to the same extent as those of the present series) the body length had increased in the test rats, as compared with normal controls of the same body weight. The increase amounted to 6 per cent. in those underfed to the age of 3 weeks, 9 per cent. in those underfed to 6 weeks, and 13 per cent. in those underfed to 10 weeks.

As shown by the data in Table 2, the rats of the present series on ample refeeding after the various inanition periods rapidly regain their normal weight-length proportions. In those underfed from birth to 3 weeks of age (body weight about $10 \mathrm{gm}$.) and refed to a body weight of $25 \mathrm{gm}$., the body (nose-anus) length has apparently not yet reached its normal ratio, however, being still 6 per cent. greater than in the normal controls. Rats of the same group refed to body weights of 50 and $75 \mathrm{gm}$. show normal lengths, however, the difference of 2 per cent. being doubtless within the range of normal variation. The differences in the groups refed after underfeeding to 6 and 10 weeks are probably likewise of no significance.

The tail was found by Stewart ${ }^{3}$ (1918) to become relatively elongated in rats underfed from birth to 3,6 or 10 weeks of age. His data show an average increase of about 44 per cent., 38 per cent., and 61 per cent., respectively, as compared with normal controls of the same body weight.

As is evident from our Table 2, such rats, on ample refeeding to a body weight of $25 \mathrm{gm}$. or more, rapidly recover the normal tail ratio. The plus or minus differences do not exceed 5 or 6 per cent., and are probably within the range of normal variation. Although there is a difference in tail length according to sex (the tail in the female being slightly longer), a grouping of the data according to sex leads to the same conclusion as to recovery of the normal tail length. The sexes are, therefore, combined in the table.

A similar elongation of the body and tail was observed in rats held at maintenance (constant body weight), beginning at 3 weeks of age, by Jackson, ${ }^{15}$ who noted that the tail normally undergoes relative elongation in the growing young rats at this period. Stewart ${ }^{2}$ found that the abnormal body length and tail ratio in rats held at maintenance from the age of 3 to 12 weeks disappears rapidly on

15. Jackson, C. M.: Changes in the Relative Weights of the Various Parts, Systems and Organs of Young Albino Rats Held at Constant Body Weight by Underfeeding for Various Periods, J. Exper. Zool. 19:99, 1915. 
ample refeeding, the normal proportions usually being regained within one week.

Head, Limbs and Trunk.- In rats underfed from birth to 3 weeks of age, Stewart ${ }^{3}$ (1918) found a relative increase of about 16 per cent. in the weight of the head, in comparison with normal controls of the same body weight. In those underfed to 6 or 10 weeks of age, however, the head was nearly normal, the difference not exceeding 4 per cent.

The data from the present series (Table 2) indicate that such rats on refeeding to $25 \mathrm{gm}$. body weight, or more, rapidly regain their normal relative head weight. It is doubtful whether the slight underweight ( -5.8 and -5.7 per cent.) of the head in the first two groups has any special significance.

Jackson $^{15}$ found little if any increase in head weight in rats held at maintenance from age of 3 to 10 weeks, and Stewart ${ }^{2}$ found nearly normal head weight in such rats throughout the period of refeeding.

Although there is considerable change in the normal proportions of the limbs and trunk of the rat during the postnatal growth period (Jackson and Lowrey ${ }^{16}$ ), there appears to be no marked or constant change in their relative weight in the young during various periods of underfeeding and refeeding (Jackson, ${ }^{15}$ Stewart, ${ }^{2,3}$ 1916, 1918). Likewise, in the present experiments, as shown by Table 2, the proportions of the forelimbs, hindlimbs and trunk remain nearly normal. The apparent differences are comparatively small, and are probably due chiefly to normal variability and experimental error. Allowance must be made for the difficulty in removing the limbs in a uniform manner.

The Integument.-In rats underfed from birth, Stewart ${ }^{3}$ (1918) found no appreciable change in the relative weight of the integument at 3 weeks of age, though at 6 and 10 weeks there was a loss of 43 to 48 per cent., compared with normal controls of the same body weight.

In the present series, assuming that the integument was likewise normal in weight in the rats underfed from birth to 3 weeks, it is difficult to account for the apparent loss of 20.1 per cent. on ample refeeding to a body weight of $25 \mathrm{gm}$. (Table $2, \mathrm{~A}$ ). In the succeeding groups, the recovery of normal relative weight is apparent. In the rat refed to $75 \mathrm{gm}$. after underfeeding from birth to 10 weeks (Table . $2, \mathrm{~F})$, there is even an apparent overgrowth of the integument $(+32.3$

16. Jackson, C. M., and Lowrey, L. G.: On the Relative Growth of the Component Parts (Head, Trunk and Extremities) and Systems (Skin, Skeleton, Musculature and Viscera) of the Albino Rat, Anat. Rec. 6:449, 1912. 
per cent.), although this may be merely an accidental variation. It is difficult to remove the integument in a uniform manner, due to the underlying subcutaneous layer and dermal sheet of musculature.

In rats underfed at later periods, beginning at three weeks of age, Jackson ${ }^{15}$ found losses of 36 per cent. or more in the integument; and Stewart ${ }^{2}$ found that in such rats the integument recovered its normal relative weight after two weeks or more of ample refeeding.

Skeleton.-The term "ligamentous skeleton" is used to designate the fresh skeleton together with the attached cartilages, periosteum and ligaments. The "cartilaginous skeleton" was prepared by immersion of the ligamentous skeleton for about one hour in 1 per cent. aqueous "Gold Dust" solution (a soap mixture) at about $95 \mathrm{C}$., so as to remove all the fibrous tissues. The cartilaginous skeleton, after rinsing in clean water, was first weighed in the moist condition. Then it was dried for several days in an wven at about $85 \mathrm{C}$., to constant weight.

As shown by the data of Stewart $^{3}$ (1918), in rats underfed from: birth the skeleton shows a remarkable persistence of growth. In the ligamentous skeleton, the relative increase at 3,6 and 10 weeks (compared with normal controls of the same body weight) is 19,13 and 24 per cent., respectively. In the moist cartilaginous skeleton, the increase is much greater, amounting to 94,33 and 54 per cent., respectively, at the same periods. In the dry skeleton, the corresponding increases. reach the astonishing figures of 166,46 and 100 per cent. Thus the growth of the skeleton during inanition was accompanied by a great increase in the amount of dry substance, together with other indications of the normal process of skeletal development.

The present data (Table 2) show that on ample refeeding to body weights of from 25 to $75 \mathrm{gm}$. after such periods of underfeeding, the skeleton in general rapidly recovers its normal proportions. Excepting the first group, the ligamentous skeleton in all cases has nearly normal relative weight. The cartilaginous skeleton, both moist and dry, even shows a definite tendency to lag behind that in normal controls of the same body weight, especially in those underfed to 6 and 10 weeks (excepting the female refed to $75 \mathrm{gm}$.). The data are not conclusive, as there is some difficulty in securing uniformity of technic in the removal of the skeleton, but they suggest the possibility that -the early inanition period, while not preventing the immediate growth of the skeleton, may produce an effect which tends to inhibit the skeletal growth at later periods, even on ample refeeding.

Persistent increase in length, indicating continued growth of the skeleton in malnourished human infants and children, has been noted: 
by Variot, ${ }^{17}$ Freund, ${ }^{18}$ Birk $^{19}$ and Hess. ${ }^{20}$ A similar persistent skeletal growth during inanition in young animals was observed in calves by Waters $^{21}$ (1908), and by Aron ${ }^{\circ 2}$ in puppies. The first extensive and detailed study of the matter was by Jackson, ${ }^{1 \tilde{5}}$ who found a marked increase in the skeletons of albino rats held at maintenance by underfeeding from 3 to 10 weeks of age. Stewart ${ }^{2}$ found that in such rats, on ample refeeding, the skeleton recovers its normal relative weight within two weeks.

Musculature.- In young rats underfed from birth to the age of 3 , 6 or 10 weeks, Stewart ${ }^{3}$ (1918) found only a slight increase of from 8 to 12 per cent. in the weight of the musculature, compared with normal controls of the same body weight.

The present data (Table 2) indicate that this slight disproportion in the musculature of such rats has disappeared on ample refeeding to $25 \mathrm{gm}$. or more of body weight. In those refed after underfeeding to 6 and 10 weeks there is, on the contrary, a slight deficit ( -5.7 to -15.4 per cent.) in the weight of the musculature. This deficit is of somewhat doubtful significance, but may indicate that the earlier inanition period has a retarding effect on the later growth of the musculature.

In rats held at maintenance by underfeeding from 3 to 10 weeks of age, Jackson ${ }^{15}$ found but a very slight increase ( 3 per cent.) in the weight of the musculature; and Stewart ${ }^{2}$ found the musculature of such rats nearly normal in weight after one week of ample refeeding.

Visceral Group and "Remainder."-The visceral group includes all of the individual organs listed in Table 2. As shown by Stewart ${ }^{3}$ (1918) the weight of the combined visceral group increases relatively in young rats underfed from birth to 3,6 or 10 weeks, the increase being 28, 29 and 38 per cent., respectively.

The present data (Table 2) show that in general this excess weight of the visceral group has disappeared in such rats when amply refed

17. Variot, G.: La dissociation de la croissance dans l'atrophie et l'hypotrophie infantiles; atrophie ponderale, atrophie staturale, Bull. et mém. Soc. méd. d. hôp. de Paris, 24:1347, 1907. Also in Bull. Soc. de pédiat. de Paris 9:363, 1907 .

18. Freund, W.: Zur Pathologie des Längenwachstums bei Säuglingen und über das Wachstum debiler Kinder, Jahrb. f. Kinderh. 70:752, 1909.

19. Birk, W.: Unterernährung und Längenwachstum beim neugeborenen Kinde, Berl. klin. Wchnschr., J. 48 2:1227, 1911.

20. Hess, Alfred F.: Infantile Scurvy. III. Jis Influence on Growth (Length and Weight), Am. J. Dis. Child. 12:152, iY16.

21. Waters, H. J.: The Capacity of Animals to Grow Under Adverse Conditions, Proc. 29th Ann. Meeting, Soc. for Promotion of Agric. Sc. 1908, 71-96. Ihid. The Influence of Nutrition on Animal Form, Presented at the Thirtieth Meeting of the Society for the Promotion of Agricultural Science, 1909.

22. Aron, Hans: Nutrition and Growth, I, Philippine J. Sc., B. 6:1, 1311. 
to 25,50 and $75 \mathrm{gm}$. in body weight. The differences are probably due chiefly to accidental variation. There are, however, differences among the various individual organs, which will be considered later. It should be remembered that the weight of the visceral group is dominated largely by the weight of a few larger organs, such as the brain and alimentary tract.

In rats held at maintenance by underfeeding, beginning at the age of 3 weeks, Jackson ${ }^{15}$ found in the visceral group a definite increase at 6 and 8 weeks, less marked at 10 weeks. On amply refeeding such rats, Stewart ${ }^{2}$ found that the visceral group recovered normal relative weight within a week.

The "remainder" is obtained by subtracting the weight of the integument, ligamentous skeleton, musculature and viscera from the net body weight (intestinal contents excluded). This "remainder" includes various small, unweighed organs, dissectable fat, body fluids, and loss by evaporation, etc. In rats underfed from birth, Stewart ${ }^{3}$ (1918) found a very marked loss in the weight of the remainder at 3 weeks ( -40 per cent.), with smaller losses at 6 and 10 weeks $(-19$ and -23 per cent.).

The present data (Table 2) show that in such rats the loss in the "remainder" has been more than fully recovered on ample refeeding to a body weight of $25 \mathrm{gm}$. or more, excepting the one female underfed to 10 weeks and refed to $75 \mathrm{gm}$. The considerable excess in Groups D and $\mathrm{E}$ is of uncertain significance, since the "remainder" is notably variable.

In rats held at maintenance by underfeeding from 3 to 6,8 or 10 weeks of age, Jackson ${ }^{15}$ found but little change in the weight of the "remainder"; and Stewart ${ }^{2}$ found it about normal after various periods of refeeding.

Brain.-In rats underfed from birth to 3 weeks, Stewart ${ }^{3}$ (1918) found a remarkable increase in the weight of the brain, the average (sexes combined), amounting to 60 per cent. gain in comparison with normal controls of the same bodyweight. In rats with continued underfeeding to 6 or 10 weeks of age, the excess in brain weight was much less, being 3 and 8 per cent., respectively.

In contrast with this overweight of the brain in the underfed rats, the present data (Table 2) show a uniform underweight of the brain in rats similarly underfed and subsequently amply refed to a bodyweight of from 25 to $75 \mathrm{gm}$. In Group D the deficit is small (-4.2 per cent.), but in the other five groups it is considerable $(-11.7$ to -22.5 per cent.). This indicates clearly that in spite of the persistent growth of the brain during the earlier underfeeding period, it has been in some way affected by the inanition, so that its later growth 
on ample refeeding is somewhat retarded, at least within the period of the present experiments.

Hatai $^{23}$ noted an apparent decrease of 4 or 5 per cent. in the weight of the brain in malnourished young rats with protein-poor diet. In a series similarly underfed and then placed on full normal diet, Hatai ${ }^{8}$ found later full recovery in the weight of the body and central nervous system. In another underfed series $^{24}$ the brain weight apparently remained normal. Donaldson ${ }^{25}$ observed a slight increase of the brain weight in rats held nearly at maintenance by underfeeding from 30 to 51 days of age. Jackson ${ }^{14}$ found the brain weight nearly constant in rats held at maintenance by underfeeding from 3 weeks of age for various periods, and Stewart ${ }^{2}$ found the brain weight normal (in proportion to body weight) in such rats on ample refeeding for various periods.

In a more recent investigation, Stewart ${ }^{26}$ found an excess of 33 per cent. in the brain weight of rats underfed from birth to 3 weeks of age (body weight $10 \mathrm{gm}$.) and of 30 per cent. in those underfed to 8 weeks (body weight $12 \mathrm{gm}$.). In another series starved more severely so as to hold them at birth weight for an average of 16 days, a remarkable increase of 114 per cent. in the brain weight was found. Stewart further demonstrated that during its growth in these underfeeding periods the brain shows normal growth in the relative weight of its various parts (excepting perhaps the olfactory bulb).

Variot and Lassablière ${ }^{27}$ likewise found the growth of the brain in malnourished human infants to be retarded less than the increase in body weight, the brain thus increasing at the expense of other parts of the body.

Spinal Cord.-In rats underfed from birth, Stewart ${ }^{3}$ (1918) found (in comparison with normal controls of the same body weight) a relative increase of 70 per cent. in the weight of the spinal cord at 3 and 10 weeks of age, and of 38 per cent. at six weeks.

23. Hatai, S.: The Effect of Partial Starvation on the Brain of the White Rat, Am. J. Physiol. 12:116, 1904.

24. Hatai, S.: Preliminary Note on the Size and Condition of the Central Nervous System in Albino Rats Experimentally Stunted, J. Compar. Neurol. and Psychol. 18:151, 1908.

25. Donaldson, H. H.: The Effect of Underfeeding on the Percentage of Water, on the Ether-Alcohol Extract, and on the Medullation in the Central Nervous System of the Albino Rat, J. compar. neurol. 21:139, 1911.

26. Stewart, Chester A: Changes in the Weights of the Various Parts, Systems and Organs in Albino Rats Kept at Birthweight for Various Periods, Am. J. Physiol. 48:67, 1919. Ibid., Weights of Various Parts of the Brain in Normal and Underfed Albino Rats at Different Ages, J. Compar. Neurol. 29:511, 1918.

27. Variot and Lassablière: Autonomie du développement de l'encéphale dans les retards de la croissance chez les jeunes enfants, Compt. rend. Soc. de biol. 66: 106,1909 . 
The present series (Table 2) show an apparent underweight of the spinal cord in such rats when amply refed to a body weight of 25 to $75 \mathrm{gm}$. The only exception is in the first group (A), which shows a slight excess of 5.4 per cent. The deficits in the other groups are small and probably insignificant, except in Groups $E$ and F. Here the deficits of 7.5 and 11.2 per cent. suggest that the longer underfeeding period may have an inhibitory after effect on the growth of the spinal cord, similar to that found in the brain.

Donaldson $^{25}$ likewise observed an increase in the spinal cord of rats held at maintenance by underfeeding from 30 to 51 days of age, and $\mathrm{Hatai}^{8}$ found a recovery of normal weight in rats subjected to partial starvation at 1 month of age and then placed on full normal diet. Jackson ${ }^{15}$ found an increase of 36 per cent. in the weight of the spinal cord of rats held at maintenance from 3 to 10 weeks of age, and Stewart ${ }^{2}$ showed that normal relative weight of the cord was obtained within two weeks of ample refeeding.

Eyeballs.-In rats underfed from birth to 3, 6 or 10 weeks, Stewart ${ }^{3}$ (1918) found a relative increase in the weight of the eyeballs (compared with normal controls of the same body weight) amounting to 41,34 and 66 per cent., respectively.

The present data (Table 2) indicate a small overweight (with one exception) in such rats amply refed to from 25 to $75 \mathrm{gm}$. in body weight. As the excess in but one case (Group D) exceeds 10 per cent., the interpretation is somewhat doubtful. It is possible that the overgrowth of the eyeballs during inanition may persist somewhat longer than in other organs during the subsequent refeeding period.

A continued growth of the eyeballs was observed by Jackson ${ }^{15}$ in rats held at maintenance by underfeeding from 3 weeks of age for various periods. At 10 weeks the excess was 50 per cent. In such rats, Stewart ${ }^{2}$ found a recovery of normal weight in the eyeballs after 4 weeks of refeeding.

Hypophysis and Pineal Body.-In rats underfed from birth to 3, 6 or 10 weeks of age, Stewart found in the weight of the hypophysis relative increases of 33,8 and 24 per cent., respectively. No sexual difference in the weight of the organ appeared under these conditions.

The present data (Table 2) indicate that in such rats amply refed to reach a body weight of from 25 to $75 \mathrm{gm}$., the hypophysis has returned nearly to normal relative weight, the differences being probably within the range of normal variation and experimental error. There is in Group $C$ a sexual difference in the size of the normal hypophysis, as seen in Groups D and $E$, where the same control rats are separated according to sex. If in Group $C$ the controls and test 
rats are grouped separately according to sex, however, the test rats show a decrease in the hypophysis of both sexes, the result being similar to that shown in the table, where the sexes are combined.

In rats held at maintenance by underfeeding from 3 to 10 weeks of age, Jackson ${ }^{15}$ noted an increase of 18 or 19 per cent. in the weight of the hypophysis. The normal difference according to sex did not appear. In such rats, on ample refeeding, Stewart ${ }^{2}$ found the hypophysis weight somewhat variable, but apparently within the normal range of variation. The volumetric and histologic changes in the hypophysis during inanition and refeeding have been described in detail by Jackson. ${ }^{28}$

The pineal body appears to undergo no constant change in weight in rats underfed from birth to 3,6 or 10 weeks of age, according to Stewart ${ }^{3}$ (1918).

As seen in Table 2, the present data, with one exception (Group D) show in such rats when amply refed to from 25 to $75 \mathrm{gm}$. body weight a relative loss in the weight of the pineal body, varying from 5.6 to 25.2 per cent. This would seem to indicate that early inanition (especially when prolonged) tends to inhibit the later growth of the pineal body. But the small size of the gland and the relatively few observations makes the conclusion somewhat uncertain.

In rats held at maintenance from 3 to 12 weeks of age, Stewart ${ }^{2}$ found an apparent loss in the weight of the pineal body, with recovery after from two to four weeks of refeeding. In rats underfed for longer periods, the results were variable. No sexual difference appears in the weight of the pineal body, as has been found to occur normally in the hypophysis, suprarenal and parathyroid glands (Hatai, Jackson).

Thyroid Gland.--In rats underfed from birth to 3, 6 or 10 weeks of age, Stewart ${ }^{3}$ (1918) found no constant change in the relative weight of the thyroid gland.

In the present series (Table 2) there appears to be a slight relative loss (4.0 to 15.6 per cent.) in the rats underfed from birth and refed to 25 or $50 \mathrm{gm}$. body weight. The three groups refed to $75 \mathrm{gm}$. are above normal, though in all the differences ( 4.9 to 7.2 per cent.) are probably within the range of normal variation.

In rats held at maintenance from 3 to 10 weeks of age, Jackson ${ }^{15}$ found a marked loss in the weight of the thyroid gland. Stewart ${ }^{2}$ concluded that such rats (after maintenance from 3 to 12 weeks of age) on ample refeeding four weeks or more had probably regained normal thyroid weight, although there appeared a slight deficit of

\footnotetext{
28. Jackson, C. M.: Effects of Inanition and Refeeding on the Growth and
} Structure of the Hypophysis in the Albino Rat, Am. J. Anat. 21:321, 1917. 
6.2 per cent. The histologic changes in the thyroid and parathyroid glands during inanition are described by Jackson. ${ }^{29}$

Thymus.-During inanition in young rats, the thymus undergoes the well-known "hunger involution" which has been described in detail by Hammar and his pupils. In rats underfed from birth to 3, 6 or 10 weeks, Stewart ${ }^{3}$ (1918) found losses in the relative weight of the thymus of 30,60 and 80 per cent., respectively.

The present data (Table 2 ) are somewhat variable, indicating that in such rats amply refed to body weight of from 25 to $75 \mathrm{gm}$. the thymus in most cases still remains somewhat below normal weight.

In rats held at maintenance from 3 to 10 weeks of age, Jackson ${ }^{15}$ found a loss of 90 per cent. in the weight of the thymus. According to Stewart, ${ }^{2}$ this loss is fully recovered after between two and four weeks of ample refeeding. At four weeks of refeeding there was even an apparent "overcompensatory" growth of the thymus, which does not appear in the present series of experiments.

Jonson $^{30}$ underfed a rabbit ( 6 weeks old) for 31 days, the body weight increasing meanwhile from 553 to $655 \mathrm{gm}$. After ample refeeding for 3 weeks, the weight of the thymus was found equal to that of a normal control killed at 6 weeks of age. Salkind ${ }^{31}$ found that at least one week of refeeding is required to restore the normal lymphoid structure of the thymus in (adult) rats after two days of acute inanition.

Heart.-In rats underfed from birth, Stewart ${ }^{3}$ (1918) found little change in the weight of the heart at 3 weeks of age, but a relative increase of 13 per cent. at six weeks and of 27 per cent. at ten weeks.

The present data (Table 2) show the heart practically normal in weight in such rats amply refed to 25,50 and $75 \mathrm{gm}$. in body weight after underfeeding from birth to 3 or 6 weeks. The apparent increases (19.3 and 13.8 per cent.) on refeeding after underfeeding from birth to 10 weeks are of doubtful significance.

In rats held at maintenance for various periods beginning at the age of 3 weeks, Jackson ${ }^{15}$ found the heart nearly normal in weight. On refeeding after maintenance from 3 to 12 weeks of age, Stewart ${ }^{2}$ found the heart probably nearly normal in weight, though somewhat above the Wistar norm in the earlier stages of refeeding.

Lungs.-In rats underfed from birth to the age of 3,6 or 10 weeks, Stewart ${ }^{3}$ (1918) found the weight of the lungs about 26 per cent. below that of normal controls with the same body weight.

29. Jackson, C. M.: Effects of Inanition on the Structure of the Thyroid and Parathyroid Glands of the Albino Rat, Am. J. Anat. 19:305, 1916.

30. Jonson, A.: Studien über die Thymusinvolution. Die Akzidentelle Involution bei Hunger, Arch. f. mikr. Anat. 73:390, 1909.

31. Salkind, J.: Contributions histologiques à la biologie comparée du thymus, Arch. de zool. exper. 55: Fasc. 5, 1915. 
The present data (Table 2) indicate that the lungs in such rats underfed from birth to 3 or 6 weeks and then amply refed to a body weight of from 25 to $75 \mathrm{gm}$. have usually recovered their normal weight. The apparent overweight in the lungs in those refed after underfeeding to 10 weeks is perhaps due to unrecognized pathologic conditions, which frequently occur in the lungs of the older rats.

In rats held at maintenance by underfeeding from 3 weeks of age for various periods, an average loss of about 15 per cent. in the weight of the lungs was observed by Jackson. ${ }^{15}$ Stewart ${ }^{2}$ found that in such rats the lungs regained their normal weight within the first weeks of ample refeeding, with an apparent overweight after longer periods of refeeding.

Liver.-In rats underfed from birth to 3, 6 or 10 weeks of age, Stewart $^{3}$ (1918) noted increases of 17,83 and 64 per cent., respectively, in the relative weight of the livers.

The present data (Table 2) are somewhat irregular, but indicate that in such rats amply refed to a body weight of from 25 to $75 \mathrm{gm}$. the liver weight, as a rule, is probably within the limits of normal variability.

In rats held at maintenance by underfeeding from the age of 3 weeks, Jackson ${ }^{15}$ found that the liver tends to gain in weight in the earlier periods, but to lose in weight later. On ample refeeding after maintenance from 3 to 12 weeks of age, Stewart ${ }^{2}$ found the liver normal in weight after one week. There was some apparent hypertrophy (probably due to accidental variation) in the rats refed four weeks or more.

Spleen.-In rats underfed from birth to 3 weeks of age, Stewart ${ }^{3}$ (1918) found a loss of 49 per cent. in the relative weight of the spleen, while in those underfed from birth to 6 or 10 weeks there was a gain of 31 or 23 per cent., respectively.

The present data (Table 3 ) indicate that on ample refeeding of such underfed rats there is found an overweight of the spleen at body weight of $25 \mathrm{gm}$. (52.1 per cent.), and of $50 \mathrm{gm}$. (33.8 and 112 per cent.) ; but normal or underweight on refeeding to $75 \mathrm{gm}$. (-24.3 and - 11.4 per cent.). This suggests a tendency to overcompensatory growth on refeeding for a short time, with a tendency to lag behind later.

This idea is supported by results of inanition experiments beginning on somewhat older rats. In rats held at maintenance from 3 weeks of age, Jackson ${ }^{15}$ found the spleen nearly normal in weight at 6 weeks, with considerable decrease later ( -42 per cent. at 10 weeks). On amply refeeding such rats after maintenance from 3 to 12 weeks 
of age, Stewart ${ }^{2}$ found rapid recovery of the normal weight of the spleen in one-half week, followed by apparent overgrowth (overcompensatory hypertrophy?) in the following two weeks, but with normal weight after four weeks or more of refeeding. Final conclusions must be guarded, however, since in weight the spleen is known to be one of the most variable organs in the body (Jackson ${ }^{4}$ ).

Stomach and Intestines.-The stomach and intestines are of especial interest in connection with the subject of inanition. They will be considered first in regard to their weight and second in regard to length.

A. Weight of Stomach and Intestines.-In rats underfed from birth to 3, 6 or 10 weeks, Stewart ${ }^{3}$ (1918) found increases of 24, 54 and 98 per cent., respectively, in the relative weight of the empty stomach and intestines (including mesentery and pancreas). In the stomach and intestine with contents, there was a loss of 25 per cent. in weight at three weeks, with gains of 104 and 55 per cent. above normal at 6 and 10 weeks, respectively.

The present data (Table 2) indicate that on refeeding such rats to body weight of from 25 to 75 gm., the empty canal apparently remains above normal weight in all except Group $D$. Those underfed from birth to 3 weeks have become practically normal at body weight of 75 gm., however. The others may require a longer time to reach the normal proportions. The canal with contents appears in general more nearly normal in weight.

In rats held at maintenance from 3 weeks to 6,8 or 10 weeks of age, Jackson ${ }^{15}$ found the empty stomach and intestines increased in weight 60,48 , and 28 per cent., respectively. Somewhat similar increase was also found in the canal with contents, which are watery or mucous in character in the rats during inanition. On refeeding after maintenance from 3 to 12 weeks of age, Stewart ${ }^{2}$ found the tract, both empty and with contents, usually returned to nearly normal weight after two weeks.

B. Length of Intestines.-The growth changes previously described in the weight of the alimentary canal during inanition might be due to changes in length, in caliber or in thickness of the wall. Some measurements on the lengths of the large and small intestine have therefore been made by Stewart, and the average data are recorded in Table 3. The intestines were measured in an extended condition, after being slit open for the entire length, the contents and mesentery being removed. In addition to the rats listed in Table 1, some observations on other individuals, used in other investigations by Stewart ${ }^{3}$ (1918 and 1919) are included. 
Unfortunately, the length of the stomach was not recorded, so the canal as measured is not strictly comparable with the weight given in Table 2. The approximate weight of the intestines (plus mesentery). however, may be estimated by subtracting the corresponding weight of the stomach and pancreas, according to the data of Hatai. ${ }^{32}$ The result indicates that the curve of growth in the weight of the intestines alone is somewhat similar to that for the entire tract. The weight of the intestines apparently increases much more rapidly than the body weight, its relative (percentage) weight increasing about fourfold between birth and the age of 6 weeks. In the meantime, as shown by the data in Table 3, the length of the intestines has also increased more rapidly than the body length, their ratio increasing from about 4.3 at birth to 7.3 at 49 days of age. This relative increase in the length of the intestine is insufficient alone to account for its increase in weight, however, hence there must also be a certain amount of increase in its caliber or in thickness of the wall, or both.

As to relative length of the large and small intestine (Table $3, \mathrm{~A}$ ), in all except the new-born group the ratio remains fairly constant between 7.4 and 7.8. This would indicate somewhat uniform rate of growth in length in both large and small intestines.

In the groups underfed from birth (Table 3, B), there is a marked increase in the lengths of both large and small intestines, which is especially marked in those held at birth weight for 19 days and those underfed to 10 weeks of age. This agrees with the increased weight of the tract, observed by Stewart ${ }^{3}$ (1918 and 1919). In the group held at birth weight, the relative increase in length appears greater in the large intestine $(+81$ per cent. $)$ than in the small $(+25$ per cent.). In the remaining groups, the increase appears to affect both large and small intestines more nearly in equal proportion.

In the rats amply refed after underfeeding from birth to 3, 6 and 10 weeks of age, the intestines in general still appear relatively long (compared with normal controls of the same body weight) in the rats refed to body weight of $25 \mathrm{gm}$. In those refed to $50 \mathrm{gm}$. the intestinal length is usually a little above normal, and in those refed to $75 \mathrm{gm}$., a little below normal. Excepting the latter group, the changes in length of the intestines in the refed groups correspond in general to the changes in weight of the canal (including stomach) previously shown. There is not much change in the relative lengths of the large and small intestines, as indicated by their ratios (Table 3 ).

32. Hatai, S.: On the Weight of the Epididymis, Pancreas, Stomach and of the Submaxillary Glands of the Albino Rat (Mus norvegicus albinus) According to Body Weight, Am. J. Anat. 24:71, 1918. 
Suprarenal Glands.-In rats underfed from birth to 3 or 6 weeks, Stewart $^{3}$ (1918) found a relative increase of about 60 per cent. in the weight of the suprarenals, while in rats underfed to 10 weeks the increase reached 114 per cent.

The present data (Table 2) indicate that in such rats amply refed to 25,50 and $75 \mathrm{gm}$. body weight the suprarenals have returned nearly to normal proportions. Groups $B$ and $C$ show essentially the same result when the data are treated separately according to sex, so they are combined in the table for economy of space. Group $\mathrm{A}$ is below the weight at which a sexual difference in the weight of the suprarenal appears.

In rats held at maintenance from 3 weeks of age, Jackson ${ }^{15}$ found a slight increase in the weight of the suprarenals at 6 and 8 weeks, with a marked increase at 10 weeks ( 39 per cent. in males, 12 per cent. in females). On refeeding such rats fully after maintenance from 3 to 12 weeks, the suprarenals appeared slightly below the controls in weight during the first four weeks, and normal thereafter. The volumetric and histologic changes in the suprarenal during inanition and refeeding are discussed in detail by Jackson. ${ }^{33}$

Kidneys.-In rats underfed from birth to 3,6 or 10 weeks of age, Stewart ${ }^{3}$ (1918) finds in the kidneys increases in relative weight amounting to 21,45 and 38 per cent., respectively.

The present data (Table 2 ) indicate that in such rats amply refed to a body weight of 25 to $75 \mathrm{gm}$. the kidneys have in general returned to nearly normal proportionate weight. In Groups $E$ and $F$, the kidneys are still above normal (17.9 and 14.7 per cent., respectively), possibly because sufficient time has not yet elapsed to allow full recovery of the normal proportions.

In rats held at maintenance from 3 weeks of age, Jackson ${ }^{15}$ found a definite tendency to increase in weight of the kidneys at 6 and 8 weeks, with but slight increase $(+4.1$ per cent.) at 10 weeks. On refeeding fully after maintenance from 3 to 12 weeks of age, Stewart ${ }^{2}$ found the kidneys normal in weight throughout the various periods.

Testes and Epididymides.-In rats underfed from birth to 3, 6 and 10 weeks of age, Stewart ${ }^{3}$ (1918) found the testes 188, 62 and 51 per cent., respectively, above normal weight. The epididymides showed corresponding gains of 95 and 13 per cent. at 3 and 6 weeks, with a loss of 6 per cent. at 10 weeks of age.

The present data (Table 2 ) indicate that in such rats the relative overweight of the testes at the end of the underfeeding period appar-

33. Jackson, C. M.: The Postnatal Development of the Suprarenal Gland and the Effects of Inanition on Its Growth and Structure in the Albino Rat, Am. J. Anat. 25: No. 3, 1919. 
ently persists to a certain extent $(+17.5$ and 19.2 per cent. $)$ in the rats amply refed to a body weight of 25 or $50 \mathrm{gm}$. In those refed to 75 gm., the marked loss ( -44.6 and -49.4 per cent.) suggests that possibly the earlier inanition in some way affects unfavorably the later growth of the testes. The effects on the epididymides are not so marked, but they also show subnormal weight in the groups refed to a body weight of $75 \mathrm{gm}$.

In rats held at maintenance from 3 to 10 weeks of age, Jackson ${ }^{15}$ found an increase of 34 per cent. in the weight of the testes, with uncertain results in the epididymides. On refeeding after maintenance from 3 to 12 weeks of age, Stewart ${ }^{2}$ obtained somewhat variable results; the testes and epididymides appeared somewhat below normal in the earlier refeeding periods, but normal later.

Ovaries.-In rats underfed from birth to 3,6 and 10 weeks of age, Stewart ${ }^{3}$ (1918) found relative increases in the weight of the ovaries amounting to 83, 91 and 54 per cent., respectively.

The present data (Table 2) for the ovaries in such rats amply refed to a body weight of 25,50 or $75 \mathrm{gm}$. are somewhat variable and inconclusive. Those refed after underfeeding to 3 weeks show a moderate overweight $(+22.3$ and +15.8 per cent. $)$ at 25 and $75 \mathrm{gm}$., but a slight loss ( -3.7 per cent. ) at $50 \mathrm{gm}$. Those refed after underfeeding to 10 weeks show a marked loss ( -20.4 and -28.6 per cent.), suggesting that the prolonged inanition period may affect unfavorably the later growth of the ovary.

In rats held at maintenance from 3 weeks of age, Jackson ${ }^{15}$ found a slight gain in the ovaries at 6 weeks, but a marked loss $(-27$ per cent.) at 10 weeks. In rats refed after maintenance from 3 to 12 weeks of age, Stewart ${ }^{2}$ found a tendency to overweight of the ovaries in the earlier refeeding periods, normal after four weeks, and underweight in adults. Conclusions are difficult on account of the large variation in the weight of the ovaries due to their normal functional cycles, but the evidence indicates that early inanition may permanently affect the later growth of the ovaries, even though the unfavorable effects may apparently disappear for a time during the earlier periods of refeeding.

\section{DISCUSSICN}

From previous investigations (cf. summary by Jackson and Stewart ${ }^{1}$ (1918), it is known that the growth of the various organs and parts in underfed young rats varies greatly, not only in different organs, but in the same organ according to the age of the animal and the extent and severity of the inanition period. Organs which in early and shorter periods of inanition increase considerably in weight may later barely maintain themselves or may even lose weight. In general, as 
age advances, the growth reactions in organ weights during inanition tend to approach those found during inanition in adults. Generally speaking, the growth reaction of an organ in a young animal during inanition will vary according to the intensity of normal growth in that organ at a corresponding normal body weight, but there are numerous exceptions to this rule. The most striking growth reactions in many of the organs are found in rats held at birth weight for two or three weeks, a period when the normal growth rate in general is most rapid (Stewart, ${ }^{3}$ 1919).

Since the normal growth rate and the growth during inanition vary so greatly according to age and other factors in the various organs, it would naturally be expected that the rate and extent of recovery on ample refeeding might likewise vary according to circumstances. The evidence at present available demonstrates that this is the case in young rats refed after different periods of inanition. We have seen in the present series of experiments that the results in some organs vary, not only according to the length of the refeeding period (whether to 25,50 or $75 \mathrm{gm}$. body weight), but also according to the length of the preceding inanition period.

That the process of recovery on refeeding will also vary according to the age at which the preceding inanition period began is evident if the results of the present experiments (beginning at birth) are compared with those published earlier by Stewart ${ }^{3}$ (1918), in which the rats were amply refed after maintenance by underfeeding beginning at 3 weeks of age. In the rats in which the inanition tests began at the later age, most of the organs (excepting the testes, epididymides and suprarenals, which remained subnormal) had recovered approximately their normal relative weight within from two to four weeks. of refeeding. The thymus, and possibly the lungs, spleen and ovaries, were apparently even above normal (overcompensatory growth?) after from two to four weeks of refeeding. In the present experiments, in which the underfeeding began at birth, we find somewhat different results. In general, inanition at the earlier age seems to have effected more permanent results, as reflected in the more tardy recovery of normal weight in several of the organs. The suprarenals, it is true, do not appear subnormal; but to the testes and epididymides we must add (for the present series) the cartilaginous and the dry skeleton, brain, spinal cord, thymus, and perhaps the pineal body, thyroid gland and ovaries, as showing more or less retarded recovery in weight on refeeding. There is no evidence of overcompensatory growth in the thymus and ovaries of the present series, and the overweight of the lungs in both cases is perhaps abnormal. In the present series, however, there usually appears a distinct hypertrophy of the 
intestinal canal, and possibly of the eyeballs. The possibility of an early overcompensatory growth in the spleen as well as the testes, followed by later retardation in growth, is also recognized.

There is some difficulty in making direct comparison between the present series and that of Stewart, ${ }^{2}$ as they differ more or less in the length of the preceding inanition and subsequent refeeding periods, as well as in the age at which the experiments began. Moreover, it must always be remembered that the number of observations is too small for anything but provisional conclusions. More extensive data will doubtless modify the results to some extent. The final effects on the various organs in the rats underfed at different periods and later refed to their maximum size (adult) will be considered in a separate article.

\section{SUMMARY}

From the data in the present series of refeeding experiments, the following provisional conclusions are indicated:

1. In albino rats underfed from birth to 3,6 or 10 weeks of age, rapid growth in body weight ensues on ample refeeding. Body weights of from 25 to $75 \mathrm{gm}$. are apparently reached more rapidly in those refed after underfeeding to 10 weeks of age than in those refed after underfeeding for shorter periods.

2. The body length remains slightly above normal in the group refed to $25 \mathrm{gm}$. body weight, but appears nearly normal in the others. The tail length and the weights of the head, limbs and trunk appear nearly normal in all the refed groups.

3. As to the body systems, the integument appears subnormal in weight in the group refed to $25 \mathrm{gm}$., usually normal (or above) in the others. The ligamentous skeleton appears nearly normal in all refed groups, but the cartilaginous skeleton (moist or dry) tends to be subnormal in weight. The musculature is nearly normal in weight, with a slight apparent deficit in the later refeeding periods. The visceral group (as a whole) and the "remainder" show no constant or significant variations in the refed groups.

4. The individual organs differ greatly in the extent to which they have recovered their normal weight (compared with that in controls. of the same body weight) in the various groups refed to a body weight. of 25,50 or $75 \mathrm{gm}$. after underfeeding from birth to 3,6 or 10 weeks of age. The weights of the various organs in the refed rats are as. follows.

The hypophysis and suprarenal glands are apparently nearly normal in weight in all groups; likewise the heart, lungs and kidneys, excepting an apparent overweight (of doubtful significance) in the groups 
refed after underfeeding to 10 weeks of age. The liver is rather irregular in weight, but probably within the range of normal variation.

The brain, spinal cord and thymus appear almost constantly subnormal in weight in all test groups. The apparent loss in the pineal body is of somewhat uncertain significance. The thyroid gland appears subnormal on refeeding to 25 and $50 \mathrm{gm}$. after underfeeding to three weeks; otherwise normal. The ovaries are irregular in weight, apparently subnormal in those refed after underfeeding to 10 weeks. The epididymides appear subnormal on refeeding to body weight of $75 \mathrm{gm}$.

The empty stomach and intestines are usually above normal weight in the refed groups; the canal with contents appears more nearly normal in weight. The length of the intestines is somewhat above normal on refeeding to $25 \mathrm{gm}$. body weight; nearly normal later. There is little change in the relative lengths of large and small intestines. The eyeballs show a slight overweight, of doubtful significance.

Two organs show an apparent tendency to overcompensatory growth in the earlier stages of refeeding, with later retardation. The spleen is greatly above normal weight at body weight of 25 or $50 \mathrm{gm}$.; but normal or subnormal at body weight of $75 \mathrm{gm}$. The testes show a similar reaction, the apparent atrophy in the later stages of refeeding being especially marked. 